\title{
How to Use a Prioritised Approach for Treating Hematological Disorders During the COVID-19 Pandemic in India?
}

\author{
Arihant Jain $^{1} \cdot$ Charanpreet Singh $^{1} \cdot$ Rishi Dhawan $^{2} \cdot$ Nishant Jindal $^{1} \cdot$ \\ Ritin Mohindra ${ }^{1} \cdot$ Deepesh Lad $^{1} \cdot$ Gaurav Prakash $^{1}$ • Alka Khadwal ${ }^{1}$. \\ Vikas Suri $^{1}$ - Ashish Bhalla ${ }^{1}$ - Savita Kumari ${ }^{1}$. Neelam Varma ${ }^{3} \cdot$ M Joseph John ${ }^{4}$. \\ Manoranjan Mahapatra ${ }^{2} \cdot$ Pankaj Malhotra $^{1}$ (D)
}

Received: 9 April 2020/Accepted: 2 June 2020/Published online: 6 June 2020

(c) Indian Society of Hematology and Blood Transfusion 2020

\begin{abstract}
The current pandemic coronavirus, SARS-CoV2 , is known to cause severe infection (COVID-19) in patients with comorbidities, particularly cancer or an immunosuppressed state. Most healthcare systems in the country are likely to be overwhelmed soon if the pandemic moves to a stage of community transmission. Currently, limited evidence is available for managing patients with hematological disorders during the COVID-19 pandemic. The current review summarises the possible challenges clinicians are likely to face, key considerations to guide decision making, and possible solutions to the anticipated challenges. Disease specific recommendations and possible guidance for decision making have been suggested for most hematologic diseases that are feasible in our health setup. It is not meant to replace individual clinical judgment, but to provide a template to formulate local policies.
\end{abstract}

Keywords COVID-19 · Hematology $\cdot$ Cancer · Pandemic . Transplant

Pankaj Malhotra

hematpgi@gmail.com

1 Department of Internal Medicine, Postgraduate Institute of Medical Education and Research (PGIMER), Chandigarh 160012, India

2 Department of Hematology, All India Institute of Medical Education and Research, New Delhi, India

3 Department of Hematology, Postgraduate Institute of Medical Education and Research, Chandigarh, India

4 Department of Clinical Haematology, Christian Medical College and Hospital, Ludhiana, India

\section{Introduction}

Patients suffering from cancers are vulnerable to the effects of the COVID-19 [1]. Early epidemiological studies from China have shown that cancer patients are at a higher risk of not only getting the COVID-19 infection, but also having a severe infection [2]. The pooled prevalence of COVID-19 in cancer patients was found to be $2 \%$ in a recent meta-analysis [3]. While the overall case fatality rates from COVID-19 have been reported from 1.4 to $2.4 \%$, patients with cancer have been reported to be at a 3.5 times higher risk of acquisition of disease and a case fatality rate reported to be $5.6 \%$ [1]. Another retrospective study from 3 centres in China showed a mortality rate of $28.6 \%$ in patients with cancer. Patients who received antitumor therapy within 14 days prior to infection had a higher risk of severe infection [4]. Both these studies had patients with solid malignancies only and a small sample size. Therefore, it may not be possible to extrapolate this data to a wider population, particularly to patients with hematological cancers. On the other hand, data from multiple studies during the H1N1 pandemic showed that patients with hematological malignancies had longer hospital stays and more severe disease, particularly in the post hematopoietic stem cell transplant setting [5-7]. A recent analysis from the UK showed that patients with hematological malignancies were at a more than threefold higher risk of hospital mortality due to COVID-19 upto five years from the hematologic diagnosis and nearly double the risk thereafter [8]. Thus, extra caution is warranted while dealing with patients suffering from hematological disorders who are going to be more vulnerable to the direct and indirect perils of the COVID-19 pandemic. 


\section{Problem Statement and Need for Change in Existing Practise}

We are in a unique situation with regards to the management of patients suffering from hematologic disorders in India. India is currently on the cusp of a major epidemic. The COVID-19 outbreak has already started to overwhelm the health care infrastructure of the country. India has 0.8 physicians per 1000 people according to the latest World Bank data estimates [9].The reasons why we need to change our time tested practise of hemato-oncology in the current pandemic are multiple. Firstly, hemato-oncology patient care consumes reasonable resources in terms of hospital beds, blood and component support, laboratory support and manpower [10]. A surge in the number of COVID-19 patients has diverted a lot of health care resources, particularly in terms of manpower, from clinical and laboratory fields to deal with the pandemic. A large number of health care personnel are frequently quarantined, making them unavailable to contribute to patient care. Therefore, hematologists may be required to use hospital resources sparingly, without unduly compromising patient care. Secondly, hematologic disorders per se, and therapy for these disorders predispose the patients to higher risks of acquiring infections, including COVID-19, as well as higher mortality. Thirdly, travel restrictions and prolonged lock downs limit access to health care professionals and certain medications and stem cell products etc. Finally, visits to crowded hospitals exposes the patients to the increased risk of acquiring the infection from other patients or even health care personnel. Healthcare facilities can act as potential epicentres of infection that can neutralise the effects of social isolation policies of the government [11].

Currently there is scarce evidence to guide therapeutic decisions for the care of hematology patients during the COVID-19 pandemic and therefore decision making is likely to be challenging. Given the extraordinary amount of rapidly evolving data and recommendations, it may be impossible for the clinicians to stay abreast of all the information. The goals of this document are to provide "expert clinical recommendations" that can serve as a template for the hematologists of the country to formulate local policies to decrease the morbidity and mortality of patients suffering from hematological disorders. Detailed guidance regarding hematopoietic stem cell transplant is beyond the scope of this review. The reader may refer to excellent reviews and guidelines on these topics [12, 13].

\section{General Recommendations to the Haematologists}

In general, decisions regarding therapy must be considered on an individual needs basis. The goal should be to free the number of beds and reduce the number of individuals attending/entering the health care facility. If a decision is made to deliver/continue curative intent therapy, all attempts should be made to deliver therapy at the nearest centre of convenience where the physicians accustomed to deal patients with hemato-oncology patients are available [14]. While current telemedicine guidelines from the government of India do not allow prescription of anti-cancer chemotherapy (being schedule $\mathrm{X}$ drugs), an attempt must be made to communicate with local practitioners to deliver chemotherapy in consultation with the primary physician treating the hematologic malignancy [15]. The importance of clear communication and careful consideration of patients perspectives cannot be over emphasized and is required at every step of decision making in this time [16]. Table 1 summarises the challenges and general recommendations which can be implemented in Indian scenario.

In the following sections we discuss a prioritised approach to guide disease specific decision making for the care of hematology patients (Table 2).

\section{Key Considerations to Guide Decision Making for the Care of Hematology Patients During the COVID 19 Pandemic}

(A) The current priority of intervention based on the disease status: In a short span of time, most accepted norms of hemato-oncology care have been transformed to that of necessity, even in the developed countries. Therapeutic interventions for hematologic disorders need to be classified based on priority in the Indian scenario as well [17]. Various guidelines have used different criteria to prioritize these therapeutic interventions. Based on their ease of applicability, we recommend to use the ESMO guidelines that classify the interventions into the following tiers [18]:

- High priority - "Patient condition is immediately life threatening, clinically unstable, and/or the magnitude of benefit qualifies the intervention as high priority [e.g. significant overall survival (OS) gain and/or substantial improvement in quality of life (QoL)]" qualifies as high priority.

- Intermediate priority - "Patient situation is noncritical, but delay beyond 6 weeks could potentially impact overall outcome and/or the magnitude of benefit" qualifies as intermediate priority.

- Low priority - "Patient condition is stable enough that services can be delayed or shifted to telemedicine for the duration of the COVID-19 pandemic and/or the intervention is non-priority based on the magnitude of benefit (e.g. no 
Table 1 Expected Challenges and proposed solutions during the COVID-19 pandemic

Challenge Proposed solutions

Reduced mobility of patients due to movement restrictions

Over-crowding in hospital outpatient department (OPD), inpatient and laboratory areas

Small chemotherapy rooms/clinics

Reduced blood and blood product availability
Setting up of telemedicine/electronic app-based consultation services for follow up of patients [12]

Hospital Records database services may be contacted to share the hematology specific helpline/telemedicine portals with the previously registered patients

List of centers of convenience need to be compiled in the drainage area of referral centers

Patients may be referred to centres of convenience closest to their homes to avoid travel during follow-ups. Referral centres can liaise with non-COVID private or public hospitals and provide protocols for the continuation of therapy [19]

Encourage on-line appointment wherever feasible

Decrease the number of individuals entering the hospital by categorizing your patients in 1 of the following 3 categories based on previous hospital records/referrals:

"Keep personal appointment" as it is for must-see patients- e.g. sick/acutely ill patients who are unable to obtain medical care at another center

"Keep or move an appointment", and also transition to telehealth or phone call option

"Reschedule for the future" (able to move the appointment by at least weeks). Allow none or no more than one visitor per person

Electronic messages may be sent to patients 1-day in advance of clinic visit to screen for COVID-19 exposure/symptoms; Those with mild symptoms of upper respiratory tract infection (URTI) may be advised strict home quarantine and to report to a nearby health facility in case of danger signs and/or fulfilment of criteria of COVID testing

Install barriers or social distancing mechanisms at front desks if screening is not conducted outside of the facility

Public signages, televisions, deployment of hospital staff to

Ensure 6 feet social distance at all places

Distribute triple layer medical masks as per guidelines for patients before entering the hospital premises and use hand sanitizer as frequently as possible at all stations [21]

Designate separate "fever clinic/fever COVID19 screening zones" in each OPD at entry points to channel all patients potentially harbouring infections for screening

Encourage home collection of investigation samples wherever feasible

Limit health access to a single-point entry

Consents from the patient who seek to attend the hospital explaining the risk of COVID19 infection

Stop hospital access to vendors/medical representatives, to use digital platforms instead

Re-design any current open infusion suite to a semi-private space, with at least six feet distance between patients and/or deploy barriers between patients

Regular communication with the blood-banks to assess the supply of blood products

Restrictive blood and blood product transfusion possibility; avoid prophylactic platelet transfusions. For e.g. a "no prophylactic platelet transfusion" strategy may be adopted for asymptomatic patients with chronic bone marrow failure (including during low dose oral chemotherapy or azacitidine) and to consider no prophylactic platelet transfusions for well patients without bleeding after autologous stem cell transplantation [22]. Encourage donations through NGOs, hospital staffs [23]

Lower thresholds erythropoietin, thrombopoietin agonist, G-CSF to decrease the risks of chemotherapy induced cytopenias (Ref NCCN)

Use prophylactic tranexamic acid in patients at risk of bleeding [24] 
Table 1 continued

\begin{tabular}{|c|c|}
\hline Challenge & Proposed solutions \\
\hline $\begin{array}{l}\text { Managing patients with hematologic disorders with } \\
\text { the suspected/confirmed COVID-19 }\end{array}$ & $\begin{array}{l}\text { Admission in the hospital isolation ward/referral to dedicated COVID-19 hospital as per } \\
\text { the national policy [25] } \\
\text { Keep low threshold for testing in immunocompromised patients } \\
\text { Look and treat for co-infections } \\
\text { Management according to national guidelines if tested positive [25] } \\
\text { Monitor for drug interactions for therapies used for COVID-19 (chloroquine/remedisvir/ } \\
\text { lopinavir) with anti-cancer drugs or antifungals }\end{array}$ \\
\hline $\begin{array}{l}\text { Lack of staff preparedness and shortage of ICU beds/ } \\
\text { equipment }\end{array}$ & $\begin{array}{l}\text { Dedicate separate training teams for timely training of staff for: } \\
\text { Screening of patients for COVID-19 related symptoms } \\
\text { Isolation and sampling of suspects } \\
\text { Rational use of personal protective equipment (PPE)/masks, donning, doffing etc } \\
\text { Prioritization of treatments including palliative care [26] }\end{array}$ \\
\hline Limited drug availability & $\begin{array}{l}\text { Treating team should liaison with the local pharmacy and chemists and ensure } \\
\text { availability of all drugs which are anticipated to be used }\end{array}$ \\
\hline
\end{tabular}

Table 2 Check box for key considerations prior to determining the care of hematology patients during the COVID 19 pandemic

Current priority of intervention based on the disease status

Current status and surge capacity of health care system

Patients ease to access health care

Local epidemiology of COVID-19 in area of patient's residence

survival gain with no change nor reduced QoL)" qualifes as low priority.
Examples of different interventions on the basis of priority level are proposed in Table 3.

(B) The current status and surge capacity of health care systems: The Ministry of Health and Family Welfare, Government of India (MOHFW) has proposed to designate separate facilities or separate blocks within existing facilities to provide COVID -19 related services. These include COVID Care Centres (CCC), Dedicated COVID Health Centres (DCHC) and Dedicated COVID Hospitals (DCH)) [19]. The

Table 3 Proposed Priority level for different hematological interventions

\begin{tabular}{|c|c|}
\hline \multirow[t]{9}{*}{ High priority } & Induction therapy in acute leukemia \\
\hline & Therapy of high-risk myelodysplastic syndrome \\
\hline & Chemo-immunotherapy for newly diagnosed aggressive non Hodgkin lymphoma and Hodgkin lymphoma \\
\hline & Therapy for newly diagnosed multiple myeloma \\
\hline & Tyrosine kinase inhibitor for newly diagnosed chronic myeloid leukemia \\
\hline & Therapy for acute immune thrombocytopenia \\
\hline & Factor support for severe hemophilia with acute bleed \\
\hline & Therapy for newly diagnosed severe aplastic anemia \\
\hline & Anticoagulation for acute thrombosis \\
\hline \multirow[t]{4}{*}{ Intermediate priority } & Consolidation therapy for acute leukemia in remission \\
\hline & Salvage therapy for transplant eligible relapsed lymphoma \\
\hline & Tertiary prophylaxis in hemophilia \\
\hline & Supportive therapy for low risk myelodysplastic syndrome \\
\hline \multirow[t]{8}{*}{ Low priority } & Maintenance therapy in ALL/plasma cell dyscrasia \\
\hline & Rituximab maintenance in indolent B- Non Hodgkin lymphoma \\
\hline & Autologous stem cell transplant in multiple myeloma \\
\hline & All post therapy surveillance investigations and visits in long term survivors including post-transplant patients \\
\hline & Supportive therapy for stable myeloproliferative neoplasms \\
\hline & Salvage and palliative intent therapy for transplant in-eligible leukemia/lymphoma \\
\hline & Follow up for chronic stable immune thrombocytopenia, aplastic anemia, hemoglobinopathy, chronic thrombosis \\
\hline & Elective surgery in patients with hemophilia \\
\hline
\end{tabular}


remaining hospitals have been directed to continue/supplement the non COVID essential services, particularly for secondary and tertiary care. Still, it is anticipated that most tertiary hospitals would have to continue to provide both COVID and non COVID services. Therefore, healthcare facilities may have to continue to deliver cancer care through some strategic re-organisation of resources. The available resource status of health care facility in terms of beds, manpower and transfusion support is a key consideration before choosing the intensity of various therapies being employed for care of hematology patients.

(C) The patients ease to access health care: Unlike the developed world, a reasonable number of patients have to travel to distant places for getting advanced hematology care. While $70 \%$ of our population lives in rural India, more than $95 \%$ of cancer care is available in urban India [20]. Transport barriers and lock downs may be heterogenous across different geographical zones. Disruption of public transport can pose a serious impediment to the delivery of complex treatments, which require frequent follow ups. Before embarking on intensive therapies requiring close follow-ups and multiple hospital visits, the ease of access to an advanced health care facility over the next few months should be considered.

(D) Local epidemiology of COVID-19 in area of patient's residence: As has been stated before, cancer patients are at an increased risk of severe infection with COVID-19 infection. The local spread of the disease in the residential area of the patient is therefore an important consideration before deciding the lines of therapy. MOHFW has classified geographical quarantine areas into containment hot zones and buffer zones based on local spread. Characterization of an individual patients risk may be done utilizing the "Aarogya Setu App" launched by the government of India that takes into account the patients individual parameters as well as local epidemiology. Such technologies can be used to assess the risk and guide the therapeutic decisions.

\section{Medicolegal and Ethical Issues}

Currently, there is limited evidence-based guidance regarding anti-cancer therapy modifications in the face of pandemic. Therefore, all changes in therapy need to be taken following a detailed discussion with the patients and patient family. It is mandatory to obtain an additional consent for alternation in the treatment protocol. The preexisting informed consent proformas need to be modified appropriately stating a) the heightened risk of adverse events in the specific patient subset in the face of a pandemic and b) the uncertain risk of disease course in case of deviation from routine protocols. The medicolegal principles of health care delivery hold true even when modes of delivery are shifted to telemedicine and all clinicians need to be aware of the same and the recently updated national guidelines [15].

\section{Disease Specific Recommendations}

\section{Adult Acute Leukemia and High Risk MDS}

Acute Leukemia represents a true challenge for hematologists in the current scenario. Intensive induction chemotherapy for acute leukemia causes prolonged neutropenia, which is a risk factor for infection and febrile neutropenia. This usually requires admission and prolonged intravenous antibiotics and antifungals as well. Coupled with a high transfusion requirement, constraint in terms of beds, blood products as well as trained haematologists has posed difficulties in the continuation of standard induction therapies [27, 28].

For treatment of newly diagnosed acute lymphoblastic leukemia (ALL) in adults, we recommend low intensity induction protocols (see Table 4) be instituted in COVID hospitals if referral to a non COVID hospital is not possible. If standard induction protocols are continued, consider decreasing the anthracycline and asparaginase dose by $50 \%$ [29]. For Philadelphia chromosome positive ALL, induction with steroids, vincristine and a tyrosine kinase inhibitor (TKI) has outcomes comaparable to intensive induction protocols in adults [30]. We also recommend omission of steroids from maintenance therapy in patients who received BFM based delayed induction [31]. Moreover, a higher target absolute neutrophil count can reduce the risk of febrile neutropenia during maintenance therapy [29].

Acute myeloid leukemia (AML) also represents a hematological emergency and emergent treatment is required in most cases. Hypomethylating agents (HMAs) have been utilised as bridge therapy for high risk MDS and AML patients, and may be an alternative during the pandemic for COVID afflicted hospitals with limited resource $[32,33]$. As intermediate dose cytarabine has not shown to affect survival as compared to high dose cytarabine, the same can be used to reduce the duration of neutropenia and inpatient stay in the hospital $[34,35]$. In patients with acute promyelocytic leukemia we recommend using arsenic trioxide and all trans retinoic acid (ATO/ATRA) combination even in high risk patients considering our institutional experience of high long term term remission rates with this regimen [36].Table 4 summaries our recommendations for treatment of ALL and AML. 
Table 4 Proposed recommendations for acute leukemia and myelodysplastic syndrome in COVID afflicted areas/hospitals

\begin{tabular}{|c|c|c|}
\hline \multirow[t]{11}{*}{$\begin{array}{l}\text { Adult acute lymphoblastic } \\
\text { leukemia (ALL) }\end{array}$} & High priority & $\begin{array}{l}\text { Patients may be shifted to non-COVID hospitals for induction wherever feasible. If the same is } \\
\text { not possible: }\end{array}$ \\
\hline & & Standard induction with reduced dose anthracyclines and asparaginase [29] \\
\hline & & Or \\
\hline & & $\begin{array}{l}\text { Induction with low intensity protocol (steroids }+ \text { vincristine } \times 6 \text { weeks in extreme resource } \\
\text { constraint) }\end{array}$ \\
\hline & & Philadelphia positive ALL may be treated with vincristine + steroids + TKI) [30] \\
\hline & Intermediate & Interim capizzi maintenance in lieu of high dose methotrexate in MRD negative disease [37] \\
\hline & priority & Refer to non-COVID hospital for salvage therapy of relapsed ALL if transplant eligible \\
\hline & Low priority & Omit steroids from maintenance therapy \\
\hline & & Aim to keep absolute neutrophil count $>1 \times 10^{9} / \mathrm{L}$ during maintenance [29] \\
\hline & & Palliation for transplant in-eligible relapsed disease \\
\hline & & Post pone surveillance visits in long term survivors \\
\hline \multirow{6}{*}{$\begin{array}{l}\text { Acute myeloid leukemia } \\
\text { (AML) }\end{array}$} & High priority & Refer to non-COVID hospitals for $7+3$ induction in eligible patients. \\
\hline & & If referral is not feasible: \\
\hline & & $\begin{array}{l}\text { Bridge therapy with hypomethylating agents (HMA) or low dose cytarabine (LDAC), with or } \\
\text { without venetoclax, particularly in patients with high risk cytogenetics [32] }\end{array}$ \\
\hline & $\begin{array}{l}\text { Intermediate } \\
\text { priority }\end{array}$ & $\begin{array}{l}\text { Reduce dose of cytarabine consolidation from } 3 \mathrm{gm} / \mathrm{m}^{2} \text { to } 1.5 \mathrm{gm} / \mathrm{m}^{2} \text { and reduce number of } \\
\text { cycles to } 3 \text { [35] }\end{array}$ \\
\hline & & Use of GCSF during consolidation \\
\hline & Low priority & Palliative care for relapsed AML patients who are in-eligible for salvage/transplant \\
\hline \multirow[t]{2}{*}{ Myelodysplastic syndrome } & High priority & Prefer HMA over $7+3$ for high risk MDS \\
\hline & $\begin{array}{l}\text { Intermediate } \\
\text { priority }\end{array}$ & $\begin{array}{l}\text { Continue supportive care with eltrombopag/GCSF and long acting } \\
\text { darbopoietin } \pm \text { lenalidomide for low risk MDS }\end{array}$ \\
\hline
\end{tabular}

\section{Lymphoma and Myeloma}

High grade lymphomas may be curable in a fraction of cases, so standard RCHOP-21 needs to be continued in most cases. As DA-EPOCH R has comparable efficacy, it may be preferred over intensive regimens like Hyper CVAD, CODOXM-IVAC in adult patients of burkitt lymphoma in COVID afflicted hospitals [38]. Salvage high intensity chemotherapy regimens may not be feasible, particularly in transplant ineligible cases and may need to be omitted, considering poor rates of long term remission in patients with high grade lymphoma [39, 40]. In our centers, we have deferred high dose methotrexate consolidation for CNS prophylaxis in high grade Non Hodgkin Lymphoma (NHL) patients with a high CNS IPI, while intrathecal methotrexate is continued in view of lack of randomised data showing superiority of one modality over other [41]. End of treatment PET-CT scans can be safely omitted in high grade NHLs, if interim scans are in CR [42].

In accordance with most other guidelines, we recommend restricting therapies only for organ/life threatening diseases in case of indolent lymphoma and recommend using oral targeted therapy (e.g. Ibrutinib) wherever feasible. Considering the $\mathrm{T}$ cell immunosuppressive effects of bendamustine, we recommend other low intensity regimes with or without Rituximab [43].
While combined modality therapy has been the standard of care for early favourable Hodgkin Lymphoma (HL), increasing the number of ABVD cycles and omission of IFRT has been recommended to decrease the hospital visits. De-escalation to AVD using interim PET-CT results may reduce adverse events in advanced HL and is therefore recommended [44]. However, an escalation strategy may not be feasible in the current scenario and therefore, we recommend continuing with 6 cycles of ABVD in advanced HL. Consolidation with radiotherapy maybe an option following salvage in late relapses where autologous transplant can't be done [39]. Wherever radiation therapy is being utilised for treatment of lymphoma, hypofractionation can be used in accordance with ILROG recommendations [45]. In patients with high grade $\mathrm{T}$ cell lymphoma requiring therapy, $\mathrm{CHOP}$ over $\mathrm{CHOEP}$ can be used given the lack of proven survival advantage of the latter [46].

In patients with newly diagnosed multiple myeloma (NDMM), standard triplet VRd induction upto 6-8 cycles is the preferred regimen while VCD, VTD regimens are other valid regimens for young patients. Doublet regimens like $\mathrm{Rd} / \mathrm{Vd}$ can be given in frail patients $[47,48]$. Patients fulfilling SLiM criteria only or having isolated anemia do not have immediate threat of organ dysfunction, and we recommend close observation for them at this time [47]. In most COVID afflicted hospitals, autologous transplants 
Table 5 Proposed recommendations for lymphoma and myeloma in COVID afflicted areas/hospitals

\begin{tabular}{|c|c|c|}
\hline \multirow{8}{*}{$\begin{array}{l}\text { Aggressive non-Hodgkins } \\
\text { lymphoma }\end{array}$} & High priority & Omit bone marrow as a staging investigation if whole-body PET is done [49] \\
\hline & & $\begin{array}{l}\text { Standard RCHOP/CHOP for newly diagnosed patients of DLBCL/PMBCL/double-hit } \\
\text { lymphomas/T cell lymphoma, }\end{array}$ \\
\hline & & Omit RT after 4 RCHOP in limited stage disease $[39,50]$ \\
\hline & & DA-EPOCH-R for burkitt lymphoma [38] \\
\hline & $\begin{array}{l}\text { Intermediate } \\
\text { priority }\end{array}$ & $\begin{array}{l}\text { Omit high dose methotrexate as CNS prophylaxis, continue intra-thecal methotrexate with } \\
\text { each cycle [41] }\end{array}$ \\
\hline & & $\begin{array}{l}\text { Salvage regimes that can be delivered easily on out-patient (e.g. R-GCVP) can be used for } \\
\text { relapsed disease in transplant eligible patients }[50,51]\end{array}$ \\
\hline & Low priority & Oral metronomic therapy \pm lenalidomide/palliation for relapsed/refractory disease \\
\hline & & Omit end of treat PET if interim PET was in CR [42] \\
\hline \multirow{5}{*}{$\begin{array}{l}\text { Indolent non-Hodgkins } \\
\text { lymphoma }\end{array}$} & High priority & Treat only organ threatening disease \\
\hline & & $\begin{array}{l}\text { Oral ibrutinib/R-chlorambucil/R-CVP/R-monotherapy/chlorambucil-prednisolone over BR } \\
\text { for organ threatening disease [43] }\end{array}$ \\
\hline & $\begin{array}{l}\text { Intermediate } \\
\text { priority }\end{array}$ & Omit maintenance rituximab and immunoglobulin replacement [43] \\
\hline & Low priority & Postpone surveillance visits in asymptomatic patients \\
\hline & & Autologous transplants in CR1 for Mantle Cell Lymphoma maybe deferred \\
\hline \multirow[t]{7}{*}{ Hodgkins lymphoma } & High priority & Early favourable-ABVD $\times 4$, omit IFRT if PET negative \\
\hline & & Early unfavourable-ABVD × 4-6 \\
\hline & & Advanced-ABVD $\times 6$ \\
\hline & & De-escalate to AVD if interim PET is negative $[44,52]$ \\
\hline & $\begin{array}{l}\text { Intermediate } \\
\text { priority }\end{array}$ & Refer to non COVID hospitals for autologous transplant if asymptomatic/late relapse [44] \\
\hline & Low priority & $\begin{array}{l}\text { In relapsed/refractory disease, prefer regimens that can be given as outpatient therapy (like } \\
\text { GDP) for transplant eligible patients [44] }\end{array}$ \\
\hline & & Oral metronomic therapy for transplant in-eligible patients \\
\hline \multirow{8}{*}{$\begin{array}{l}\text { Multiple myeloma and plasma } \\
\text { cell dyscrasias }\end{array}$} & High priority & Standard 3-drug induction therapy in NDMM \\
\hline & & Doublet therapy for frail/elderly individuals \\
\hline & & Treat only patients with CRAB criteria, SLiM may wait \\
\hline & & Give first dose of anti-resorptive therapy $[47,48]$ \\
\hline & Intermediate & Postpone all transplants \\
\hline & priority & $\begin{array}{l}\text { Shift to lenalidomide maintenance after } 6-8 \text { cycles, stem cells maybe cryopreserved in } \\
\text { transplant eligible patients [48] }\end{array}$ \\
\hline & Low priority & Reduce follow up and monitoring of MGUS and smoldering myeloma \\
\hline & & Frequency of anti-resorptive therapy may be shifted to 3 monthly instead of monthly \\
\hline
\end{tabular}

need to be deferred, while stem cells may be cryopreserved after 6 cycles. Table 5 summarises our recommendations for lymphoma and myeloma.

\section{Myeloproliferative Neoplasms}

Patients suffering from myeloproliferative neoplasms (MPNs) form a major proportion of patients in hematology out-patient services. Chronic myeloid leukemia (CML) is the commonest leukemia in adults in India [53]. Majority of patients with CML and other MPNs can successfully be monitored using telemedicine to reduce visits to the hospital $[54,55]$. Patients with blast crisis can be treated with single agent second generation TKI. Those not responding, lymphoid blast phase of CML can be treated with additional vincristine and corticosteroids, while for myeloid blast crisis additional HMA can be considered rather than high intensity therapy [56]. For polycythemia vera patients, we recommend a reduction in phlebotomy frequency (target haematocrit $>48-50 \%$ ) in order to decrease visits to healthcare [57]. Low-risk polycythemia vera patients on only phlebotomy therapy can be initiated on hydroxyurea to reduce the phlebotomy frequency. While initiating new patients on JAK inhibitors (Ruxolitinib) may be deferred, those patients who already are on JAK inhibitors maybe continued [57]. Initially, concerns were raised regarding 
the use of NSAIDs during COVID-19 however at present there is no evidence of severe adverse events, acute health care utilization, long-term survival, or quality of life in patients with COVID-19, therefore aspirin can be safely continued in patients with MPN $[58,59]$.

Table 6 summarises our recommendations for MPNs.

\section{Benign Disorders}

Most benign disorders, with the exception of newly diagnosed severe aplastic anemia (SAA) and acute immune thrombocytopenia purpura (ITP), often only require only a regular out-patient follow up. The aims while managing these disorders (hemoglobinopathy, haemophilia and bleeding disorders and thrombotic disorders) should be to reduce OPD visits without increasing morbidity.

SAA on the other hand represents a medical emergency that is potentially curable disease and therefore require a high priority intervention. Hence, patients of SAA need to be given ATG/Matched sibling transplant (MSD) wherever feasible. In most other patients combination of cyclosporine, androgen and eltrombopag can be used as a bridge to anti thymocyte globulin (ATG)/transplant [61]. Prophylactic antifungals, antibiotics and acyclovir may be used in severely neutropenic patients on the basis of pervious recommendations of supportive care for patients with aplastic anemia [62].

For patients with ITP, attempts should be made to reduce exposure to immunosuppressive agents such as steroids, in favour of thrombopoetin analogues and IVIg [63]. We recommend utilising newer oral anticoagulants over vitamin $\mathrm{K}$ antagonists to reduce monitoring of INR and visits to the OPD in patients with thrombosis [64]. Looming shortages of transfusion support for patients of hemoglobinopathy are being faced at most centers in India, therefore transfusion thresholds need to be modified. Strict compliance to the advisory of MOHFW and use of online $e$-Rakt-Kosh portal can help in ensuring continued transfusion support to patients with these disorders [23]. Our recommendations for hemophilia patients are based on the a reduction in humanitarian aid and availability of clotting factors, which is occurring due to the restricted movement across countries and states. Table 7 summarises our recommendations for benign disorders.

\section{Future Directions}

Most national and international recommendations are based on "expert opinions" currently due to the paucity of data regarding the clinical impact of COVID-19 in hematologic disorders. The American Society of Hematology has started the ASH RC COVID-19 Registry for Hematologic Malignancy which encourages worldwide haematologists to share data on COVID-19 in patients with hematological conditions [65]. The real-time data in this registry is updated on the twitter handle @ASHCollab. Similarly, the Center for International Blood and Marrow Transplantation Research (CIBMTR) reports real-time data on COVID-19 in patients of hematopoietic cell transplantation on their website [66]. We would encourage reporting of COVID-19 cases in patients with hematological conditions in the Indian scenario to the Hematology Cancer Consortium so that evidence based recommendations can be made in future [67].

\section{Conclusion}

As there is limited scientific evidence currently, clinical experience and the principle of safeguarding the rights of the community over individual patient rights may guide therapeutic decision making. Physicians catering to patients with hematologic disorders also need to review and implement the rapidly evolving global and Indian and institute specific guidelines and modify them in a way that is best suited to their local situation.

Table 6 Proposed recommendations for myeloproliferative neoplasms in COVID afflicted areas/hospitals

\begin{tabular}{|c|c|c|}
\hline \multirow{5}{*}{$\begin{array}{l}\text { Chronic myeloid } \\
\text { leukemia }\end{array}$} & High priority & Continue TKI in accordance to standard guidelines \\
\hline & & $\begin{array}{l}\text { Single agent } 2 \text { nd generation TKI or reduced intensity protocols for blast crises (steroid }+ \text { vincristine }+ \\
\text { TKI for lymphoid BC and HMA/LDAC }+ \text { TKI for myeloid BC) [53] }\end{array}$ \\
\hline & Intermediate & Allogeneic transplants for advanced phase CML maybe deferred \\
\hline & priority & TFR trials may be deferred \\
\hline & Low priority & Reduce follow up; BCR ABL monitoring may be done yearly in patients in MMR \\
\hline \multirow{4}{*}{$\begin{array}{l}\text { Myeloproliferative } \\
\text { neoplasms }\end{array}$} & Moderate & Decrease frequency of phlebotomy; may consider hydroxyurea for low risk polycythemia vera [60] \\
\hline & priority & Defer starting of JAK inhibitors [54] \\
\hline & & Postpone all allogeneic transplants \\
\hline & Low priority & Reduce monitoring and increase follow up intervals \\
\hline
\end{tabular}


Table 7 Proposed recommendations for benign hematologic disorders in COVID afflicted areas/hospitals

\begin{tabular}{|c|c|c|}
\hline \multirow[t]{2}{*}{ Aplastic anemia } & High priority & $\begin{array}{l}\text { Refer patients with severe aplastic anemia to non-COVID hospital for ATG/MSD transplant } \\
\text { If the same is not feasible: } \\
\text { Cyclosporine with TPO agonists/androgens and supportive care for severe aplastic anemia [61] } \\
\text { Use more restrictive transfusion thresholds for blood and platelet transfusion }\end{array}$ \\
\hline & $\begin{array}{l}\text { Intermediate/ } \\
\text { low priority }\end{array}$ & Decrease follow up for cyclosporine monitoring \\
\hline \multirow{2}{*}{$\begin{array}{l}\text { Immune } \\
\text { thrombocytopenia } \\
\text { purpura }\end{array}$} & High priority & $\begin{array}{l}\text { Prefer IVIg or TPO agonists over steroids for treatment of acute ITP with platelet count less than } \\
10,000 / \mathrm{ul} / \mathrm{bleeding} \text { in acute ITP [63] }\end{array}$ \\
\hline & Low priority & $\begin{array}{l}\text { Reduce follow up visits in non bleeders } \\
\text { Postpone splenectomies in chronic refractory ITP } \\
\text { Use lower doses of steroids for chronic ITP; transition to oral TPO agonists wherever feasible }\end{array}$ \\
\hline Thrombosis & \multicolumn{2}{|c|}{ Prefer newer oral anticoagulants (NOACS)/bridge to NOACS wherever feasible } \\
\hline $\begin{array}{l}\text { Hemoglobinopathy } \\
\text { (thalassemia) }\end{array}$ & \multicolumn{2}{|c|}{ Modify transfusion threshold $(<7 \mathrm{gm} / \mathrm{dl})$} \\
\hline Hemophilia & High priority & $\begin{array}{l}\text { Continue on-demand therapy; consider giving short term factor prophylaxis at discharge for } \\
\text { domestic use }\end{array}$ \\
\hline & $\begin{array}{l}\text { Intermediate } \\
\text { priority }\end{array}$ & $\begin{array}{l}\text { Defer tertiary prophylaxis and prophylaxis in adults, may need to defer immune tolerance induction } \\
\text { in patients with inhibitors }\end{array}$ \\
\hline & Low priority & Defer all elective surgical and rehabilitation procedures \\
\hline
\end{tabular}

Funding None.

\section{Compliance with Ethical Standards}

Conflict of interest Authors have no conflict of interest to declare.

Human and Animals Rights The article does not involve any study with participation of humans or animals by the authors.

\section{References}

1. Wang H, Zhang L (2020) Risk of COVID-19 for patients with cancer. Lancet Oncol 21(4):e181

2. Zhou F, Yu T, Du R, Fan G, Liu Y, Liu Z et al (2020) Clinical course and risk factors for mortality of adult inpatients with COVID-19 in Wuhan, China: a retrospective cohort study. Lancet 395(10229):1054-1062

3. Desai A, Sachdeva S, Parekh T, Desai R (2020) Covid-19 and cancer: lessons from a pooled meta-analysis. JCO Glob Oncol 6:557-559

4. Zhang L, Zhu F, Xie L, Wang C, Wang J, Chen R et al (2020) Clinical characteristics of COVID-19-infected cancer patients: a retrospective case study in three hospitals within Wuhan China. Ann Oncol. https://doi.org/10.1016/j.annonc.2020.03.296 [Epub ahead of print]

5. Minnema BJ, Husain S, Mazzulli T, Hosseini-Mogaddam SM, Patel M, Brandwein J et al (2013) Clinical characteristics and outcome associated with pandemic (2009) H1N1 influenza infection in patients with hematologic malignancies: a retrospective cohort study. Leuk Lymphoma 54(6):1250-1255

6. Ljungman P, de la Camara R, Perez-Bercoff L, Abecasis M, Campuzano JBN, Cannata-Ortiz MJ et al (2011) Outcome of pandemic $\mathrm{H} 1 \mathrm{~N} 1$ infections in hematopoietic stem cell transplant recipients. Haematologica 96(8):1231-1235

7. Dignani MC, Costantini P, Salgueira C, Jordán R, Guerrini G, Valledor A et al (2015) Pandemic 2009 influenza A (H1N1) virus infection in cancer and hematopoietic stem cell transplant recipients; a multicenter observational study. F1000 Res 3:221

8. OpenSAFELY Collaborative T, Williamson E, Walker AJ, Bhaskaran K, Bacon S, Bates C et al (2020) OpenSAFELY: factors associated with COVID-19-related hospital death in the linked electronic health records of 17 million adult NHS patients. MedRxiv. https://doi.org/10.1101/2020.05.06.20092999

9. Physicians (per 1000 people) - India I Data. https://data.world bank.org/indicator/SH.MED.PHYS.ZS?locations=IN. Accessed on 14 Apr 2020

10. Ambroise MM, Ravichandran K, Ramdas A, Sekhar G (2015) A study of blood utilization in a tertiary care hospital in South India. J Nat Sci Biol Med 6(1):106-110

11. Kamel Boulos MN, Geraghty EM (2020) Geographical tracking and mapping of coronavirus disease COVID-19/severe acute respiratory syndrome coronavirus 2 (SARS-CoV-2) epidemic and associated events around the world: how 21 st century GIS technologies are supporting the global fight against outbr. Int $\mathbf{J}$ Health Geogr 19(1):8

12. Coronavirus disease COVID-19: EBMT recommendations (Update 23 Mar 2020) I EBMT. https://www.ebmt.org/ebmt/news/ coronavirus-disease-covid-19-ebmt-recommendations-updatemarch-23-2020

13. BSBMTCT recommendations for COVID adult BMT - 27 Mar 2020 - British society of blood and marrow transplantation. https://bsbmtct.org/bsbmtct-recommendations-for-covid-adultbmt-16th-march-2020/

14. Willan J, King AJ, Hayes S, Collins GP, Peniket A (2020) Care of haematology patients in a COVID-19 epidemic. Br J Haematol 189(2):241-243

15. Board of Governors (2020) In supersession of the Medical Council of India telemedicine practice guidelines enabling 
registered medical practitioners to provide healthcare using telemedicine. www.mohfw.gov.in. Accessed on 14 Apr 2020

16. Back A, Tulsky JA, Arnold RM (2020) Communication skills in the age of COVID-19. Ann Intern Med. https://doi.org/10.7326/ M20-1376 [Epub ahead of print]

17. Pramesh CS, Badwe RA (2020) Cancer Management in India during Covid-19. N Engl J Med. https://doi.org/10.1056/ NEJMc2011595

18. Cancer patient management during the COVID-19 pandemic I ESMO. https://www.esmo.org/guidelines/cancer-patient-manage ment-during-the-covid-19-pandemic. Accessed on 14 Apr 2020

19. Guidance document on appropriate management of suspect/confirmed cases of COVID-19. www.mohfw.gov.in. Accessed on 14 Apr 2020

20. Banavali SD (2015) Delivery of cancer care in rural India: experiences of establishing a rural comprehensive cancer care facility. Indian J Med Paediatr Oncol 36(2):128

21. Ministry of Health and Family Welfare Directorate General of Health Services [emergency medical relief] novel corornavirus disease (COVID-19) guidelines on use of masks by public. www. moohfw.gov.in. Accessed on 14 Apr 2020

22. Managing haematology and oncology patients during the COVID-19 pandemic: interim consensus guidance I The Medical Journal of Australia. https://www.mja.com.au/journal/2020/212/ 10/managing-haematology-and-oncology-patients-during-covid19-pandemic-interim

23. NBTC Interim guidance for blood transfusion services in view of COVID-19. https://naco.gov.in/nbtc-interim-guidance-bloodtransfusion-services-view-covid-19. Accessed on 14 Apr 2020

24. Ben-Bassat I, Douer D, Ramot B (2009) Tranexamic acid therapy in acute myeloid leukemia: possible reduction of platelet transfusions. Eur J Haematol 45(2):86-89

25. Revised National Clinical Mangement guidelines for COVID-19. www.mohfw.gov.in. Accessed on 14 Apr 2020

26. Lancet $\mathrm{T}$ (2020) Palliative care and the COVID-19 pandemic. The Lancet 395(10231):1168

27. Favre G, Fopp M, Gmür J, Tichelli A, Fey MF, Tobler A et al (1993) Factors associated with transfusion requirements during treatment for acute myelogenous leukemia. Ann Hematol 67(4):153-160

28. Lopez-Plaza I, Weissfeld J, Triulzi DJ (1999) The cost-effectiveness of reducing donor exposures with single-donor versus pooled random-donor platelets. Transfusion 39(9):925-932

29. COVID-19 and ALL - Hematology.org. https://www.hematology. org/covid-19/covid-19-and-all. Accessed on 14 Apr 2020

30. Chalandon Y, Thomas X, Hayette S, Cayuela JM, Abbal C, Huguet $F$ et al (2015) Randomized study of reduced-intensity chemotherapy combined with imatinib in adults with $\mathrm{Ph}$-positive acute lymphoblastic leukemia. Blood 125(24):3711-3719

31. McNeer JL, Nachman JB (2010) The optimal use of steroids in paediatric acute lymphoblastic leukaemia: no easy answers. Br J Haematol 149(5):638-652

32. Grunwald MR, Boselli D, Bohannon LM, Zimmerman MKA, Ai J, Knight TG et al (2018) Hypomethylating agent (HMA) treatment as a bridge to allogeneic hematopoietic cell transplantation (HCT) for relapsed/refractory acute myeloid leukemia (RRAML). J Clin Oncol 36(15 suppl):7033-7033

33. Kim Y, Kim IH, Kim HJ, Park S, Lee KH, Kim SJ et al (2014) Multicenter study evaluating the impact of hypomethylating agents as bridging therapy to hematopoietic stem cell transplantation in myelodysplastic syndromes. Int $\mathrm{J}$ Hematol 99(5):635-643

34. Wu D, Duan C, Chen L, Chen S (2017) Efficacy and safety of different doses of cytarabine in consolidation therapy for adult acute myeloid leukemia patients: a network meta-analysis. Sci Rep 7(1):9509
35. COVID-19 and acute myeloid leukemia - Hematology.org. https://www.hematology.org/covid-19/covid-19-and-acute-mye loid-leukemia. Accessed on 14 Apr 2020

36. Varma S, Yanamandra U, Khadwal A, Prakash G, Suri V, Kumari S et al (2015) High risk apml treated successfully with four cycles of ATO and ATRA combination in resource constrained settings. Blood 126(23):3322-3322

37. Jastaniah W, Elimam N, Abdalla K, AlAzmi AA, Aseeri M, Felimban S (2018) High-dose methotrexate vs. Capizzi methotrexate for the treatment of childhood T-cell acute lymphoblastic leukemia. Leuk Res Rep 10:44-51

38. Dunleavy K (2018) Approach to the diagnosis and treatment of adult burkitt's lymphoma. J Oncol Pract 14(11):665-671

39. Haematological malignancies: DLBCL, MCL and aggressive $T$ cell lymphoma in the COVID-19 era I ESMO. https://www.esmo. org/guidelines/cancer-patient-management-during-the-covid-19pandemic/haematological-malignancies-dlbcl-mcl-and-aggres sive-t-cell-lymphoma-in-the-covid-19-era. Accessed on $14 \mathrm{Apr}$ 2020

40. Coiffier B, Sarkozy C (2016) Diffuse large B-cell lymphoma: R-CHOP failure-What to do? Hematology 2016(1):366-378

41. Avilés A, Jesús Nambo M, Neri N (2013) Central nervous system prophylaxis in patients with aggressive diffuse large B cell lymphoma: An analysis of 3258 patients in a single center. Med Oncol 30(2):520

42. Jain A, Jain A, Malhotra P (2019) Re-defining prognosis of hematological malignancies by dynamic response assessment methods: lessons learnt in chronic myeloid leukemia, Hodgkin lymphoma, diffuse large b cell lymphoma and multiple myeloma. Indian J Hematol Blood Transfus. https://doi.org/10.1007/ s12288-019-01213-7

43. COVID-19 and indolent lymphomas - Hematology.org. https:// www.hematology.org/covid-19/covid-19-and-indolent-lympho mas. Accessed on 14 Apr 2020.

44. COVID-19 and Hodgkin Lymphoma - Hematology.org. https:// www.hematology.org/covid-19/covid-19-and-hodgkin-lym phoma. Accessed on 14 Apr 2020

45. Yahalom J, Dabaja BS, Umberto R et al (2020) ILROG emergency guidelines for radiation therapy of hematological malignancies during the COVID-19 pandemic. Blood 10:12-15. https://doi.org/10.1182/blood.2020006028 [Epub ahead of print]

46. Deng S, Lin S, Shen J, Zeng Y (2019) Comparison of CHOP vs CHOPE for treatment of peripheral T-cell lymphoma: a metaanalysis. Onco Targets Ther 12:2335-2342

47. UK Myeloma Forum guidance to support medical decisionmaking in the management of myeloma patients during the COVID-19 (coronavirus) outbreak. https://www.ukmf.org.uk/ guidelines/covid-19-guidance/. Accessed on 14 Apr 2020

48. COVID-19 and multiple myeloma - Hematology.org. https:// www.hematology.org/covid-19/covid-19-and-multiple-myeloma. Accessed on 14 Apr 2020.

49. Cheson BD, Fisher RI, Barrington SF, Cavalli F, Schwartz LH, Zucca E et al (2014) Recommendations for initial evaluation, staging, and response assessment of Hodgkin and non-Hodgkin lymphoma: the lugano classification. $J$ Clin Oncol 32(27):3059-3068

50. COVID-19 and aggressive lymphoma - Hematology.org. https:// www.hematology.org/covid-19/covid-19-and-aggressive-lym phoma. Accessed on 14 Apr 2020

51. Gration B, Duran A, Mir N, Yuen L, Warner M, Stanley K et al (2017) R-GCVP as second line treatment in elderly patients with DLBCL who fail R-CHOP and are not candidates for intensive therapy. Blood 130(Supplement 1):4133-4133

52. Haematological malignancies: Hodgkin lymphoma in the COVID-19 era I ESMO. https://www.esmo.org/guidelines/ 
cancer-patient-management-during-the-covid-19-pandemic/hae matological-malignancies-hodgkin-lymphoma-in-the-covid-19era. Accessed on 14 Apr 2020

53. Ganesan P, Kumar L (2017) Chronic myeloid leukemia in India. J Glob Oncol 3(1):64-71

54. Copeland A, Wehbie R, Clayton M, Black A, Rapchak B, Foster MC (2015) The feasibility of a telemedicine platform to monitor adherence and adverse effects of ABL kinase inhibitors. Blood 126(23):3308-3308

55. COVID-19 and CML - Hematology.org. https://www.hematol ogy.org/covid-19/covid-19-and-cml. Accessed on 14 Apr 2020

56. Hehlmann R (2012) How I treat CML blast crisis. Blood 120(4):737-747

57. COVID-19 and myeloproliferative neoplasms - Hematology.org. https://www.hematology.org/covid-19/covid-19-and-myeloproli ferative-neoplasms. Accessed on 14 Apr 2020

58. Little P (2020) Non-steroidal anti-inflammatory drugs and covid19. BMJ 368:m1185

59. Russell B, Moss C, Rigg A, Van Hemelrijck M (2020) COVID19 and treatment with NSAIDs and corticosteroids: should we be limiting their use in the clinical setting? Ecancermedicalscience $14: 1023$

60. Barbui T, De Stefano V, Ghirardi A, Masciulli A, Finazzi G, Vannucchi AM (2018) Different effect of hydroxyurea and phlebotomy on prevention of arterial and venous thrombosis in polycythemia vera. Blood Cancer J 8(12): 124

61. COVID-19 and aplastic anemia - Hematology.org. https://www. hematology.org/covid-19/covid-19-and-aplastic-anemia. Accessed on 14 Apr 2020.

62. Hö Chsmann B, Moicean A, Risitano A, Ljungman P, Schrezenmeier H (2013) Supportive care in severe and very severe aplastic anemia. Bone Marrow Transpl 48:168-173

63. COVID-19 and ITP - Hematology.org. https://www.hematology. org/covid-19/covid-19-and-itp. Accessed on 14 Apr 2020.

64. ten Cate H (2020) Thrombosis management in times of COVID19 epidemy; a dutch perspective. Thromb J 18(1):7

65. ASH RC COVID-19 registry for hematologic malignancy I Ash research collaborative. https://www.ashresearchcollaborative.org/ covid-19-registry.

66. COVID-19 Reported data. https://www.cibmtr.org/Covid19/ Pages/default.aspx

67. HCC: 1st annual meeting. https://www.hemecancer.org

Publisher's Note Springer Nature remains neutral with regard to jurisdictional claims in published maps and institutional affiliations. 